\title{
The 18th Top Chess Engine Championship: TCEC18
}

Article

Accepted Version

The TCEC 18 report

Haworth, G. ORCID: https://orcid.org/0000-0001-9896-1448 and Hernandez, N. (2020) The 18th Top Chess Engine

Championship: TCEC18. ICGA Journal, 42 (2-3). pp. 211-222.

ISSN 1389-6911 doi: https://doi.org/10.3233/ICG-200160 Available at https://centaur.reading.ac.uk/91839/

It is advisable to refer to the publisher's version if you intend to cite from the work. See Guidance on citing.

Published version at: https://content.iospress.com/articles/icga-journal/icg200160

To link to this article DOI: http://dx.doi.org/10.3233/ICG-200160

Publisher: The International Computer Games Association

All outputs in CentAUR are protected by Intellectual Property Rights law, including copyright law. Copyright and IPR is retained by the creators or other copyright holders. Terms and conditions for use of this material are defined in the End User Agreement.

\section{www.reading.ac.uk/centaur}

\section{CentAUR}

Central Archive at the University of Reading

Reading's research outputs online 


\section{The $18^{\text {th }}$ Top Chess Engine Championship, TCEC18}

Guy Haworth ${ }^{1}$ and Nelson Hernandez

Reading, UK and Maryland, USA

With only a short break after Season 17 (Haworth and Hernandez, 2020a/b; Sadler, 2020a) the TCEC Season 18 Championship started on May 3rd, 2020, providing a welcome focus for a world under Covid-19 constraint: thanks and kudos to 'Aloril' and the TCEC team. The structure was simplified with five divisions of no more than 10 engines, two promotions and two demotions throughout. Some engines returned to the ranks after not making the move to LINUX successfully for TCEC17 and some engines stepped away for this season. Table 1 and Figures $1 \& 5$ provided the details.

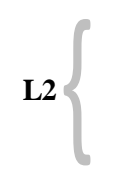

L3

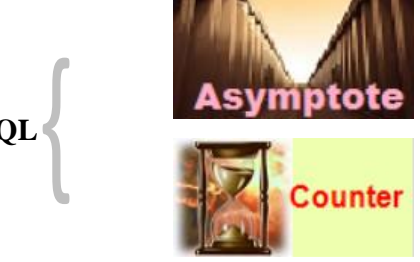

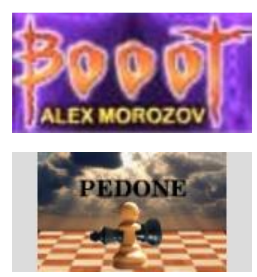
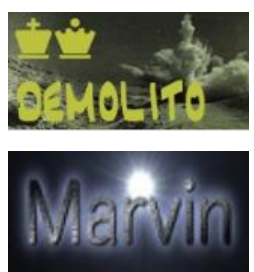
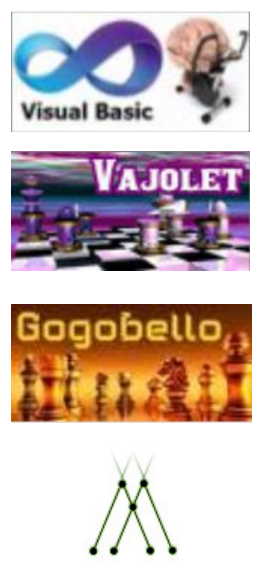
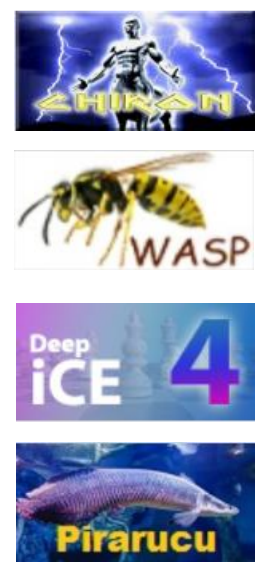
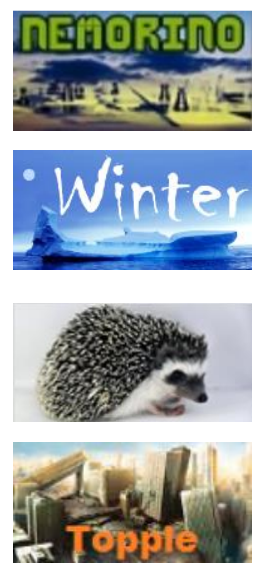

Fig. 1. The logos for the engines originally in the Qualification League and in Leagues 3 and 2.

The hardware platform for the 'Shannon AB' engines was as for TCEC17, courtesy of major sponsor 'noobpwnftw'. Four Intel (2016) Xeon E5-4669v4 processors: LINUX, 88 cores and 176 threads of activity with the Syzygy 'EGT' endgame tables in their own 1TB RAM. The NN-engines used four Nvidia (2019) V100 GPUs, a power upgrade of 9\% since TCEC17. The 'EGT' platform was less than on the CPU side: just $500 \mathrm{~GB}$ of SSD fronted by a $128 \mathrm{GiB}$ RAM buffer.

\footnotetext{
${ }^{1}$ Corresponding author: g.haworth@ reading.ac.uk
} 
Table 1. The TCEC18 engines (CPW, 2020a).

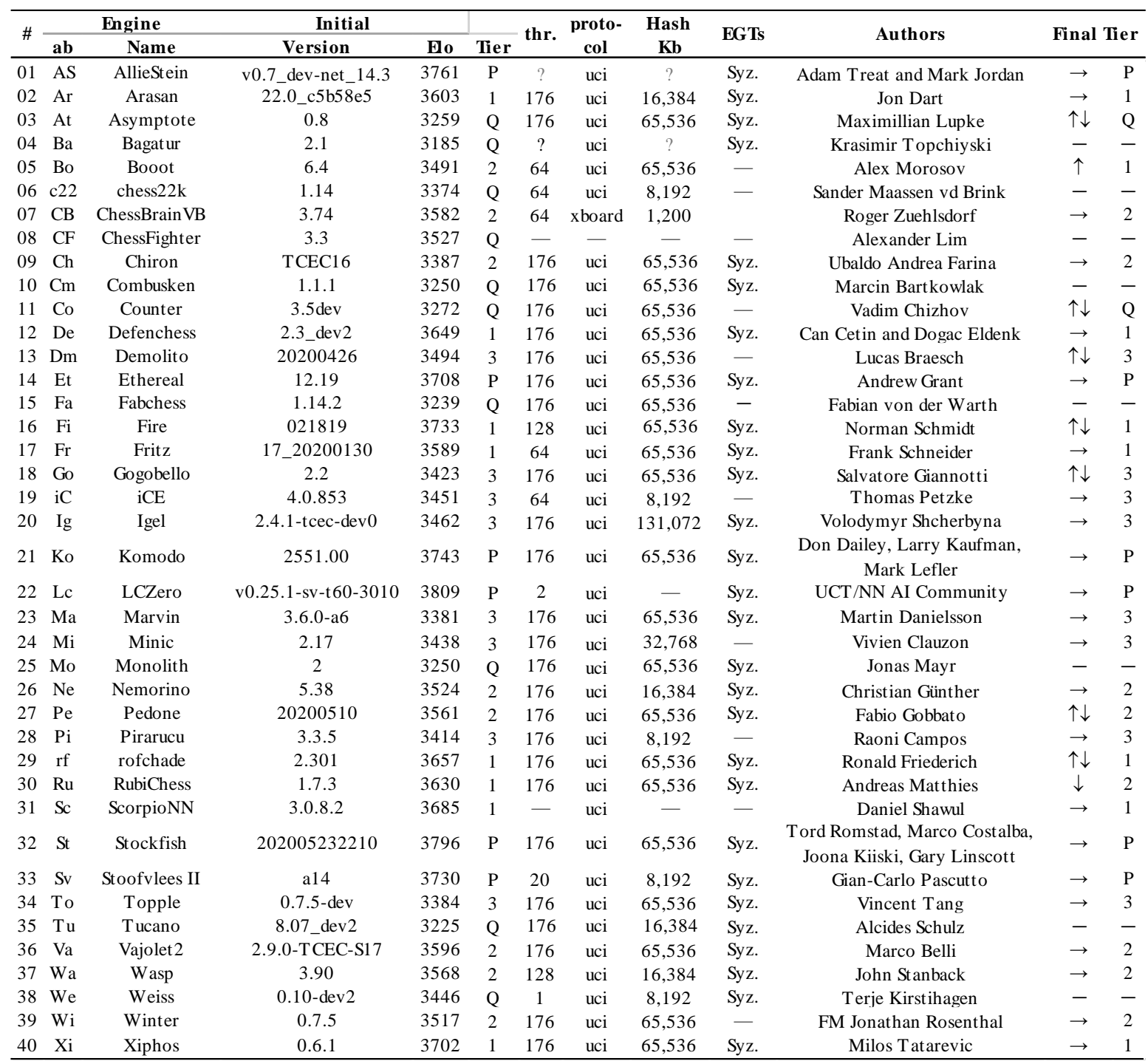

\section{THE QUALIFICATION LEAGUE: 10 ENGINES, 1 DRR, 90 GAMES @ 30'+5"/m}

TCEC welcomed returning BAGATUR, CHESS22K and MONOLITH and first-timers COMBUSKEN and WEISS. COUNTER and ASYMPTOTE, far from infallible, finally emerged as promotees just ahead of MONOLITH and CHESS22K, both of which had crucially lost to COUNTER. ASYMPTOTE had even lost to newcomer COMBUSKEN which acquitted itself well. The other novice, WEISS, had a rough initiation with the occasional draw but felt no pain.

TCEC fan 'Imabacus' (2020) provided the graphics here which convey the dynamics of each event, round by round and, with Aloril's (2020) Bayeselo data, game by game. Wool (2020) touched on games 2, 4, 5, 8, 10, 14, 22, 27-8, 42, 45, 64, 67, 69, 72-3, 79, 82-4 and 87. Endgame footnote: game 80, CHESS22K vs COMBUSKEN was a 50-move draw, pre-empting White's KQkbb win in 56. 
Table 2. The TCEC18 Qualification League cross-table.

\begin{tabular}{llcccccccccccccccc}
\hline \# Engine & Elo & Pts & X & P\% & SB & Co & At & Mo & c22 & CF & Fa & Cm & Tu & Ba & We \\
\hline 01 Counter 3.5dev & 3292 & 12.0 & 0 & 66.7 & 93.00 & & $=0$ & $=1$ & $1=$ & 00 & $1=$ & $=1$ & $1=$ & 11 & 11 \\
02 Asymptote 0.8 & 3269 & 11.5 & 0 & 63.9 & 94.50 & $=1$ & & $1=$ & $==$ & 01 & 01 & $0=$ & $1=$ & 11 & $1=$ \\
03 Monolith 2 & 3319 & 11.5 & 0 & 63.9 & 86.75 & $=0$ & $0=$ & & 01 & $==$ & $=1$ & $1=$ & $=1$ & 11 & 11 \\
04 chess22k 1.14 & 3402 & 11.0 & 0 & 61.1 & 90.00 & $0=$ & $==$ & 10 & & $=1$ & $1=$ & $==$ & $1=$ & $1=$ & $=1$ \\
05 ChessFighter 3.3 & 3470 & 10.5 & 0 & 58.3 & 85.00 & 11 & 10 & $==$ & $=0$ & & $==$ & $0=$ & $==$ & $=1$ & 11 \\
06 FabChess 1.14.2 & 3264 & 10.0 & 0 & 55.6 & 72.75 & $0=$ & 10 & $=0$ & $0=$ & $==$ & & $==$ & $1=$ & 11 & 11 \\
07 Combusken 1.1.1 & 3291 & 10.0 & 0 & 55.6 & 81.75 & $=0$ & $1=$ & $0=$ & $==$ & $1=$ & $==$ & & $=1$ & $0=$ & 11 \\
08 Tucano 8.07_dev2 & 3205 & 7.0 & 0 & 38.9 & 53.25 & $0=$ & $0=$ & $=0$ & $0=$ & $==$ & $0=$ & $=0$ & & $=1$ & $1=$ \\
09 Bagatur 2.1 & 3155 & 5.0 & 0 & 27.8 & 32.25 & 00 & 00 & 00 & $0=$ & $=0$ & 00 & $1=$ & $=0$ & & 11 \\
10 Weiss 0.10-dev2 & 3078 & 1.5 & 0 & 08.3 & 14.75 & 00 & $0=$ & 00 & $=0$ & 00 & 00 & 00 & $0=$ & 00 \\
\hline
\end{tabular}
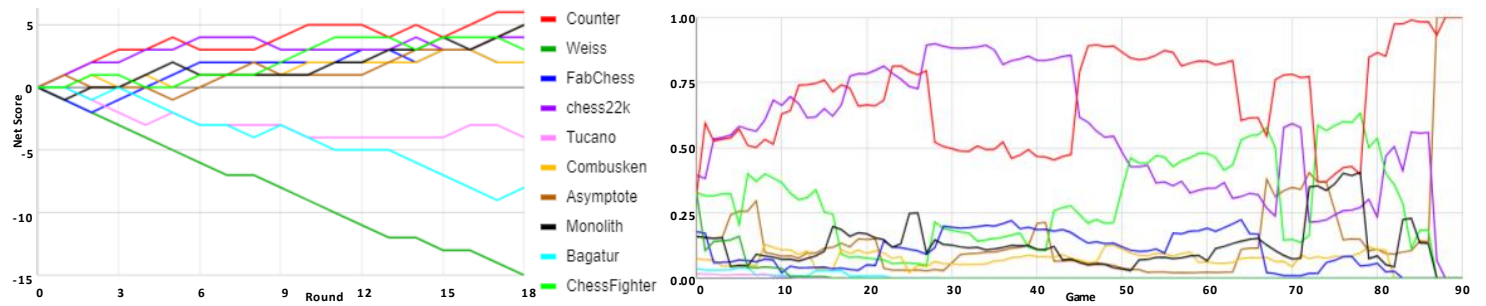

Fig. 2. Left: QL engines' net wins, round by round. Right: engines' probability of promoting, game by game.

\section{LEAGUE 3: 10 ENGINES, 1 DRR, 2RRs, 90 GAMES @ 30'+5"/m}

DEMOLITO had had a fine run in TCEC17 and was a favourite for promotion. After the first round robin, net wins at the top were DEMOLITO +4, IGEL +2, GOGOBELLO and ICE +1. Game 7, GOGOBELLO's loss to PIRARUCU should be seen retrospectively as a surprise. In the second half, IGEL went unbeaten but was overtaken by GOGOBELLO which notched up four wins.

Table 3. The TCEC18 League 3 cross-table.

\begin{tabular}{|c|c|c|c|c|c|c|c|c|c|c|c|c|c|c|c|c|}
\hline$\#$ & Engine & Elo & Pts & $\mathbf{X}$ & $\mathbf{P} \%$ & SB & De & Go & Ig & Mi & $\mathrm{iC}$ & Ma & To & $\mathbf{P i}$ & Co & At \\
\hline 01 & Demolito 20200426 & 3494 & 12.0 & 0 & 66.7 & 99.75 & & $=0$ & $==$ & $1=$ & 11 & $==$ & $1=$ & $==$ & $=1$ & 11 \\
\hline 02 & Gogobello 2.2 & 3423 & 11.0 & 0 & 61.1 & 96.75 & $=1$ & & $==$ & $1=$ & $1=$ & $==$ & $==$ & $0=$ & $=1$ & $=1$ \\
\hline 03 & Igel 2.4.1-tcec-dev0 & 3462 & 10.5 & 0 & 58.3 & 90.75 & $==$ & $==$ & & $1=$ & $0=$ & $==$ & $=1$ & $1=$ & $==$ & $1=$ \\
\hline 04 & Minic 2.17 & 3438 & 9.5 & 0 & 52.8 & 79.75 & $0=$ & $0=$ & $0=$ & & $==$ & 11 & $==$ & $1=$ & $==$ & $1=$ \\
\hline 05 & iCE 4.0.853 & 3451 & 9.0 & 0 & 50.0 & 76.25 & 00 & $0=$ & $1=$ & $==$ & & $==$ & 10 & $1=$ & $=1$ & $==$ \\
\hline 06 & Marvin 3.6.0-a6 & 3381 & 9.0 & 0 & 50.0 & 78.00 & $==$ & $==$ & $==$ & 00 & $==$ & & $==$ & $==$ & $=1$ & $=1$ \\
\hline 07 & Topple 0.7.5-dev & 3384 & 8.0 & 0 & 44.4 & 71.75 & $0=$ & $==$ & $=0$ & $==$ & 01 & $==$ & & $=1$ & $==$ & $=0$ \\
\hline 08 & Pirarucu 3.3 .5 & 3414 & 8.0 & 0 & 44.4 & 72.00 & $==$ & $1=$ & $0=$ & $0=$ & $0=$ & $==$ & $=0$ & & $==$ & $1=$ \\
\hline 09 & Counter $3.5 \mathrm{dev}$ & 3292 & 7.0 & 0 & 38.9 & 62.50 & $=0$ & $=0$ & $==$ & $==$ & $=0$ & $=0$ & $==$ & $==$ & & $==$ \\
\hline 10 & Asymptote 0.8 & 3269 & 6.0 & 0 & 33.3 & 52.00 & 00 & $=0$ & $0=$ & $0=$ & $==$ & $=0$ & $=1$ & $0=$ & $==$ & \\
\hline
\end{tabular}

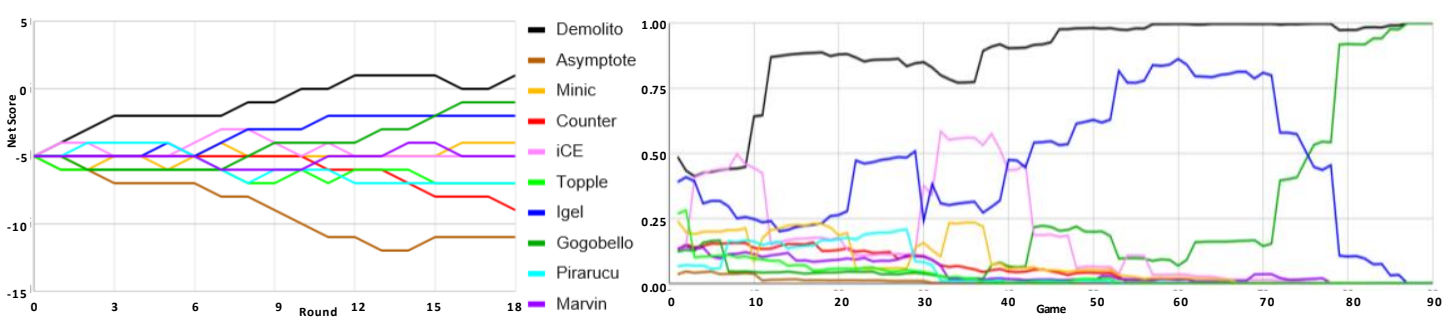

Fig. 3. Left: L3 engines' net wins, round by round. Right: engines' probability of promoting, game by game. 
DEMOLITO and GOGOBELLO duly promoted, the latter greatly helped by a win over the former. The previous promotees, COUNTER and ASYMPTOTE, enjoyed the briefest of appearances with only one win between them and went back to the Qualification League. Wool (2020) as usual provides an accessible assessment and convenient summary of some two-thirds of the decisive games in the form of light notes. $^{2}$

\section{LEAGUE 2: 10 ENGINES, 1 DRR, 2 RRs, 90 GAMES @ 30'+5"/m}

After successful transition to the LINUX platform, BOOOT, CHESSBRAINVB and CHIRON rejoined as 'top 24' TCEC engines. This was another minimal, four day, Rapid tempo event with Cato openings of 12 ply this time. At the half-way point, BOOOT and PEDONE on +5 , and WINTER on +3 were the only engines in positive territory. BOOOT had beaten CHESSBRAINVB 1-0 in game 15, CHIRON 0-1 in game 17 and VAJOLET2 0-1 in game 28. PEDONE took maximum points from what was to become the tail of this league. It also beat WINTER in game 22 which was to prove crucial in tie-break terms as 'head to head results' trumped 'number of wins'. In game 35, DEMOLITO scored a notable win over CHIRON but the other promotee, GoGOBELLO was suffering on -6 .

BOOOT and the unbeaten PEDONE promoted but WINTER kept things interesting, beating BOOOT in game 87 and drawing level on points with PEDONE. In mid-table, CHIRON eventually overcame WASP in game 59 which would have run to 164 moves in a $\mathrm{R}$ vs $\mathrm{N}$ endgame. DEMOLITO and Gogobello were relegated: promotees so far were not faring well in the higher divisions. Wool (2020) commendably provides notes on 30 games, almost all decisive, and including all the wins in the NW corner of Table 4's cross table. ${ }^{3}$

Table 4. The TCEC18 League 2 cross-table.

\begin{tabular}{|c|c|c|c|c|c|c|c|c|c|c|c|c|c|c|c|c|}
\hline \# & Engine & Elo & Pts & $\mathbf{X}$ & P\% & SB & Bo & $\mathbf{P e}$ & We & Va & Ch & Wa & CB & $\mathrm{Ne}$ & De & Go \\
\hline 01 & Booot 6.4 & 3491 & 12.5 & 0 & 69.4 & 102.50 & & $==$ & $=0$ & $1=$ & 11 & $=1$ & $1=$ & $1=$ & $=1$ & $1=$ \\
\hline 02 & Pedone 20200510 & 61 & 12.0 & 0 & 66.7 & 101.00 & $==$ & & $1=$ & $==$ & $==$ & $1=$ & $==$ & $1=$ & $1=$ & 11 \\
\hline 03 & Winter 0.7.5 & 3517 & 12.0 & 0 & 66.7 & 101.50 & $=1$ & $0=$ & & $=1$ & $==$ & $1=$ & $1=$ & $1=$ & 11 & $==$ \\
\hline 04 & Vajolet2 2.9.0-TCEC-S17 & 3595 & 9.0 & 0 & 50.0 & 73.50 & $0=$ & $==$ & $=0$ & & $0=$ & $==$ & $==$ & $==$ & $=1$ & 11 \\
\hline 05 & Chirol & 3387 & 8.5 & 0 & 47.2 & 73.25 & 00 & $==$ & $==$ & $1=$ & & $=1$ & $=0$ & $==$ & $0=$ & $1=$ \\
\hline 06 & Wasp 3.90 & 3568 & 8.5 & 0 & 47.2 & 69.00 & $=0$ & $0=$ & $0=$ & $==$ & $=0$ & & $==$ & $1=$ & $=1$ & $1=$ \\
\hline 07 & ChessBrainVB 3.74 & 3582 & 7.5 & 0 & 41.7 & 68.00 & $0=$ & $==$ & $0=$ & $==$ & $=1$ & $==$ & & $=0$ & $==$ & $=0$ \\
\hline 08 & Nemorino 5.38 & 3524 & 7.5 & 1 & 41.7 & 63.00 & $0=$ & $0=$ & $0=$ & $==$ & $==$ & $0=$ & $=1$ & & $=0$ & $1=$ \\
\hline 09 & Demolito 20200426 & 3503 & 7.0 & 0 & 38.9 & 58.00 & $=0$ & $0=$ & 00 & $=0$ & $1=$ & $=0$ & $==$ & $=1$ & & $==$ \\
\hline 10 & Gogobello 2.2 & 3436 & 5.5 & 0 & 30.6 & 48.75 & $0=$ & 00 & $==$ & 00 & $0=$ & $0=$ & $=1$ & $0=$ & $==$ & \\
\hline
\end{tabular}
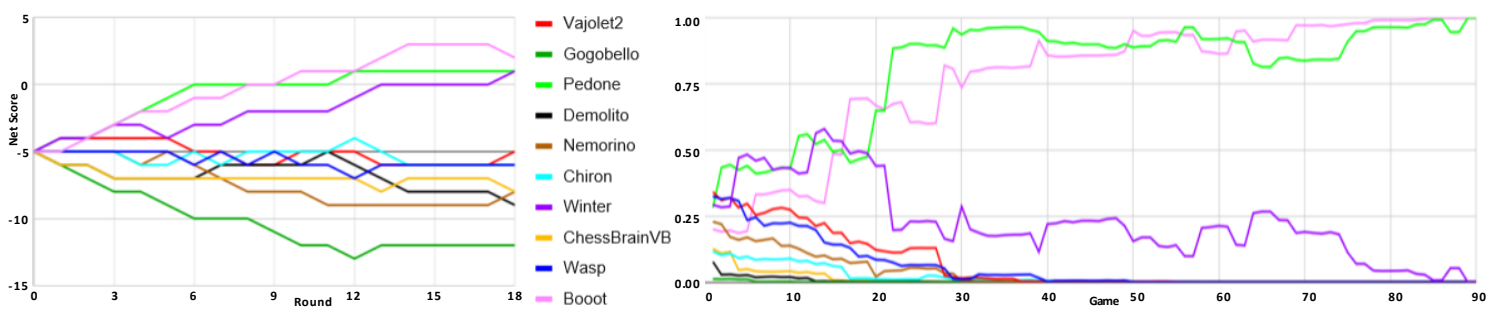

Fig. 4. Left: L2 engines' net wins, round by round. Right: engines' probability of promoting, game by game.

\footnotetext{
${ }^{2}$ Wool touched on L3 games 3, 7, 10, 12, 22, 29-30, 32-3, 38, 40, 43, 48, 53-4, 57, 59, 69, 71-2, 78-9 and 90.

${ }^{3}$ Wool noted L2 games 2, 4, 13, 15, 17-8, 20, 22, 28-30, 32, 35, 37, 39, 40, 50, 54, 58-9, 61-4, 69-70 and 87-90.
} 


\section{LEAGUE 1: 10 ENGINES, 1 DRR, 2 RRs, 90 GAMES @ 45' +5' $/ \mathrm{m}$}

This fourth event enjoyed a slightly more relaxed tempo and had 16-ply openings from Cato. FRITZ, a top 16 engine, now rejoined TCEC in LINUX mode, albeit WINE-limited like BOOOT on only 64 threads. After the first round robin, FIRE was favourite to promote on +2 with wins against BOOOT and RUBICHESS but XIPHOS, DEFENCHESS and ROFCHADE were closely engaged on +1 . BOOOT's game 27 win over FRITZ was a surprise: XIPHOS crucially beat DEFENCHESS in g30. After round robin 1, ROFCHADE beat DEFENCHESS in g67 and FRITZ in g83 to emerge from the pack as second favourite to promote. BoOOT was the first promotee in TCEC18 to remain up: its third place was more than creditable given that it was on the WINE platform. FIRE and ROFCHADE promoted. RUBICHESS and PEDONE were relegated. Wool provided the headlines on 21 games. ${ }^{4}$

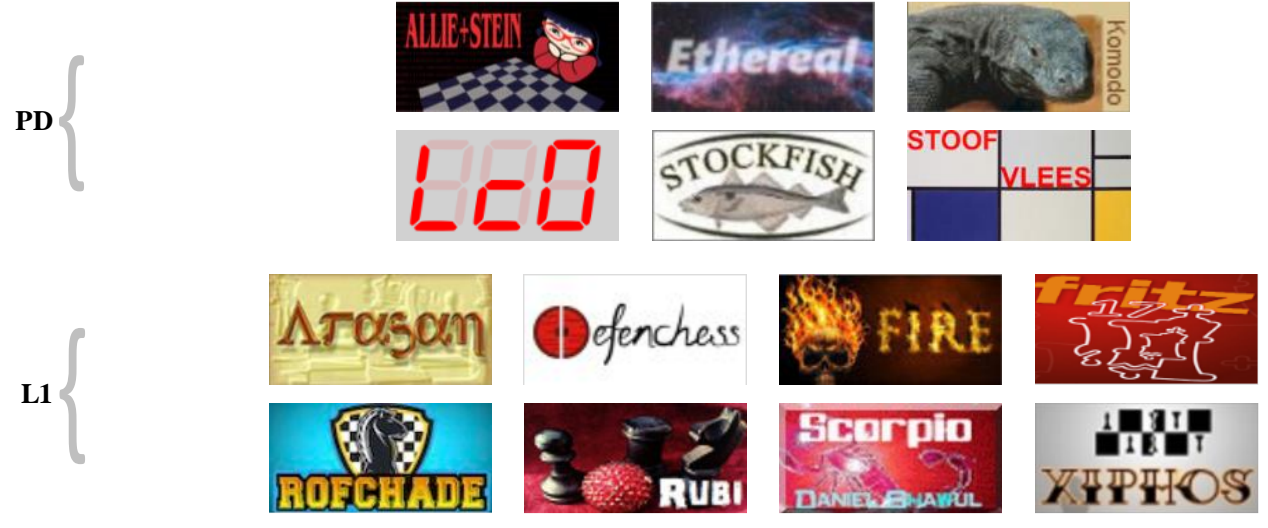

Fig. 5. The logos for the engines originally in League 1 and the Premier Division.

Table 5. The TCEC18 League 1 cross-table.

\begin{tabular}{|c|c|c|c|c|c|c|c|c|c|c|c|c|c|c|c|c|}
\hline \# & Engine & Elo & Pts. & $\bar{X}$ & $\mathbf{P \%}$ & SB & $\mathbf{F i}$ & rf & Bo & De & $\mathbf{F r}$ & $\mathbf{X i}$ & Sc & $\mathbf{A r}$ & $\mathbf{R u}$ & $\mathbf{P e}$ \\
\hline 01 & Fire 021819 & 3733 & 11.5 & 0 & 63.9 & 98.50 & & $==$ & $1=$ & $==$ & $==$ & $=1$ & $==$ & $=1$ & $1=$ & $=1$ \\
\hline 02 & rofChade 2.301 & 3657 & 11.0 & 0 & 61.1 & 94.75 & $==$ & & $==$ & $=1$ & $=1$ & $==$ & $==$ & $==$ & $=1$ & $1=$ \\
\hline 03 & Booot 6.4 & 3634 & 9.5 & 0 & 52.8 & 83.75 & $0=$ & $==$ & & $==$ & $1=$ & $==$ & $=1$ & $==$ & $==$ & 01 \\
\hline 04 & Defenchess 2.3_dev2 & 3649 & 9.5 & 0 & 52.8 & 79.75 & $==$ & $=0$ & $==$ & & $==$ & $0=$ & $==$ & $==$ & $1=$ & 11 \\
\hline 05 & Fritz 17_20200130 & 3589 & 9.0 & 0 & 50.0 & 76.25 & $==$ & $=0$ & $0=$ & $==$ & & $==$ & $==$ & $==$ & $==$ & 11 \\
\hline 06 & Xiphos 0.6.1 & 2685 & 9.0 & 0 & 50.0 & 80.00 & $=0$ & $==$ & $==$ & $1=$ & $==$ & & $==$ & $==$ & $==$ & $==$ \\
\hline 07 & ScorpioNN 3.0.8.2 & 3702 & 9.0 & 0 & 50.0 & 79.00 & $==$ & $==$ & $=0$ & $==$ & $==$ & $==$ & & $==$ & $==$ & $=1$ \\
\hline 08 & Arasan 22.0_c5b58e5 & 3603 & 8.5 & 0 & 47.2 & 75.75 & $=0$ & $==$ & $==$ & $==$ & $==$ & $==$ & $==$ & & $==$ & $==$ \\
\hline 09 & RubiChess 1.7 .3 & 3630 & 7.5 & 0 & 41.7 & 66.50 & $0=$ & $=0$ & $==$ & $0=$ & $==$ & $==$ & $==$ & $==$ & & $==$ \\
\hline 10 & Pedone 20200510 & 3575 & 5.5 & 0 & 30.6 & 50.25 & $=0$ & $0=$ & 10 & 00 & 00 & $==$ & $=0$ & $==$ & $==$ & \\
\hline
\end{tabular}

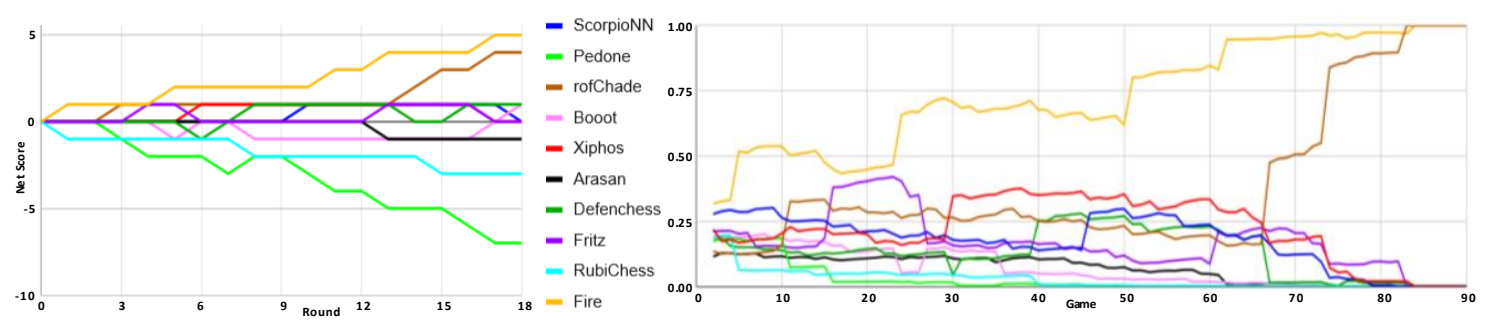

Fig. 6. Left: L1 engines' net wins, round by round. Right: engines' probability of promoting, game by game.

\footnotetext{
${ }^{4}$ Wool noted L1 games 5, 11, 16, 24, 27-8, 30-1, 36, 40, 46, 51, 61-2, 67, 74, 76, 81, 83-4 and 90.
} 
At this point, the TCEC18 championship stepped into a different, more deliberate world - a doubled time-budget and three times the round robins. The Premier Division was to take longer than the previous four divisions but, as it was to yield the two Superfinalists, interest was high and the video-commentators became active. Cato supplied 16-ply openings from his Premier Division book.

The event opened with an unexpected display of fireworks. The fancied four, the perennial superchampion STOCKFISH and the three neural-network engines LEELA, AlLIESTEIN and STOOFVLEES, were pitched against the rest. Even so, no-one expected five consecutive decisive games, two Black wins for surprise leader STOOFVLEES and a clean divide between the favourites and the followers. After the first round robin, STOCKFISH, LEELA and STOOFVLEES led on +2: the top four were unbeaten.

At the conclusion of the first set of mini-matches, STOOFVLEES was setting the event alight with +4 . It had done the double over ROFCHADE and taken 3.5/4 from the two tail-enders: Wool (2020) highlights g42, STOOFVLEES' win over FIRE. ${ }^{5}$ Had something special been added to the stew? The top four remained unbeaten though ALLIESTEIN had a borderline position against STOOFVLEES in game 54. The unthinkable, a superfinal involving neither STOCKFISH nor LEELA was entirely possible. The bottom four had no wins: the chasm between top and bottom four yawned.

The third round robin will be remembered for one thing: STOCKFISH went on a rampage with five wins from seven, victims including ALLIESTEIN, game 72 (Wool, 2020), and STOOFVLEES, game 79. With a human athlete, we would have been talking drug tests! LEELA continued undefeated, quite unaware of the carnage elsewhere. Game 72 was the first loss by an $\mathrm{NN}$-engine in this event and remained the standout game to revisit. It was also arguably one of the most spectacular games in TCEC history long-range strategy, two minor-exchange sacs, oscillating eval-curves, deep calculation and both NNkibitzers apparently off the pace. Thankfully, GM Matthew Sadler and WIM Natasha Regan (2016, 2019, 2020) help us with the complexities, covering this game extensively with rich context and appealing humility in their 'CG\#24' video. ${ }^{6}$ In game 79, STOOFVLEES' king was chased to centre field by STOCKFISH and got mated. After the seven rounds, STOCKFISH dominated on +7 ahead of LEELA's +4 , STOOFVLEES' +3 and AlLiESTEIN's +2 .

A key question for RR4 was whether STOCKFISH would defend the other side of all the games it had won. It did: losses - none, and the same went for LEELA which took clear second by beating FIRE in the last game of the round, see the Sadler/Regan's 'CG\#25' video. Even so, all three NN-engines were in the race for second: each hard-won result would change their ranking. ETHEREAL still had no wins but already seemed safe from relegation as ROFCHADE and FIRE were unwillingly cast as major donors.

RR5: it was STOCKFISH's turn to beat FIRE, g114/29.2 and next, ALLIESTEIN beat ETHEREAL. Here, a TCEC-win adjudication pre-empted what would have been an interesting, 50-move demonstration of Rook overpowering Bishop (Müller and Konoval, 2019). Two games later, we had the big surprise, ROFCHADE beating STOOFVLEES - or rather, STOOFVLEES losing to ROFCHADE with the blunder 47. Kf2??, ignoring the obvious pin. In game 129, ALLIESTEIN beat ROFCHADE to go second but in game 131, LEELA, playing Black, reclaimed the position by beating STOOFVLEES. In game 134, LEELA eased away to a win against ETHEREAL but in game 136, ALLIESTEIN stayed in touch with a win against

\footnotetext{
${ }^{5}$ Wool commented on (DRR1) games 1-5, 9, 15, 22, 25, 33, 35, 42, 44 ; (DRR2) 57-9, 61, 63, 65, 67, 72-4, 78-9, 81, 91, 98, 112; (DRR3) 114-5, 117, 121, 123, 129, 131, 134, 146, 141, 145, 154, 159 \& 164.

${ }^{6}$ In their videos, Sadler and Regan (2020) cover Premier Division games 15, 33, 57, 72, 112, 121, 134 and 164.
} 
Komodo. At the end of RR5, the standings were StOcKFISH +9 , LEELA +7 , ALLIESTEIN +6 and STOOFVLEES, wrong side of a nightmare, +2 . It was probably too late to get the money on STOCKFISH being in the Superfinal and LEELA was a surprisingly strong favourite for second.

The last round robin opened with the unattractive prospect of second place being decided by the fourth tie-breaker, Sonnerborn-Berger score. The chat room flared up accordingly with assorted counterfactual histories - missed wins, alternative tie-breaks, critique of the randomly selected openings. In fact, g164 effectively ended ALLIESTEIN's chances when it lost to KOMODO (Wool, 2020). Unusually, ALLIESTEIN was convinced it had lost well before KOMODO was convinced it had won.

Table 6. The TCEC18 Premier League cross-table.

\begin{tabular}{|c|c|c|c|c|c|c|c|c|c|c|c|c|c|c|}
\hline \# & Engine & Elo & Pts. & & $\mathbf{P \%}$ & SB & St & $\overline{\mathbf{L c}}$ & $\mathbf{A S}$ & $\mathbf{S v}$ & Ko & Et & ro & $\mathbf{F i}$ \\
\hline 01 & Stockfish 202005232210 & 3796 & 25.5 & 0 & 60.7 & 508.50 & & $======$ & $==1===$ & $==1===$ & $==1===$ & $======$ & $1=1=1=$ & $1=1=1=$ \\
\hline 02 & LCZero v0.25.1-sv-t60-3010 & 3809 & 24.5 & 0 & 58.3 & 495.25 & $=====$ & & $======$ & $====1=$ & $1=====$ & $==1=1=$ & $1=1===$ & $===1==$ \\
\hline 03 & AllieStein 0.7_dev-net_14.3 & 3761 & 23.5 & 0 & 56.0 & 471.25 & $==0===$ & $======$ & & $======$ & $====10$ & $1===1=$ & $==1=1=$ & $=1=1==$ \\
\hline 04 & Stoofvlees II a14 & 3730 & 23.0 & 0 & 54.8 & 459.75 & $==0===$ & $====0=$ & $======$ & & $1=====$ & $=====$ & $11==01$ & $=1=1=1$ \\
\hline 05 & Komodo 2551.00 & 3743 & 21.0 & 0 & 50.0 & 428.00 & $==0===$ & $0=====$ & $====01$ & $0=====$ & & $=====$ & $==1===$ & $==1=1=$ \\
\hline 06 & Ethereal 12.19 & 3708 & 19.0 & 0 & 45.2 & 399.00 & $======$ & $==0=0=$ & $0==0=$ & $=====$ & $=====$ & & $======$ & $======$ \\
\hline 07 & rofChade 2.303 & 3661 & 16.0 & & 38.1 & 336.25 & $0=0=0=$ & $0=0===$ & $==0=0=$ & $00==10$ & $==0===$ & $======$ & & $=====$ \\
\hline 08 & Fire 8 beta & 3729 & 15.5 & 0 & 36.9 & 328.00 & $0=0=0=$ & $==0==$ & $=0=0==$ & $=0=0=0$ & $==0=0=$ & $======$ & $======$ & \\
\hline
\end{tabular}

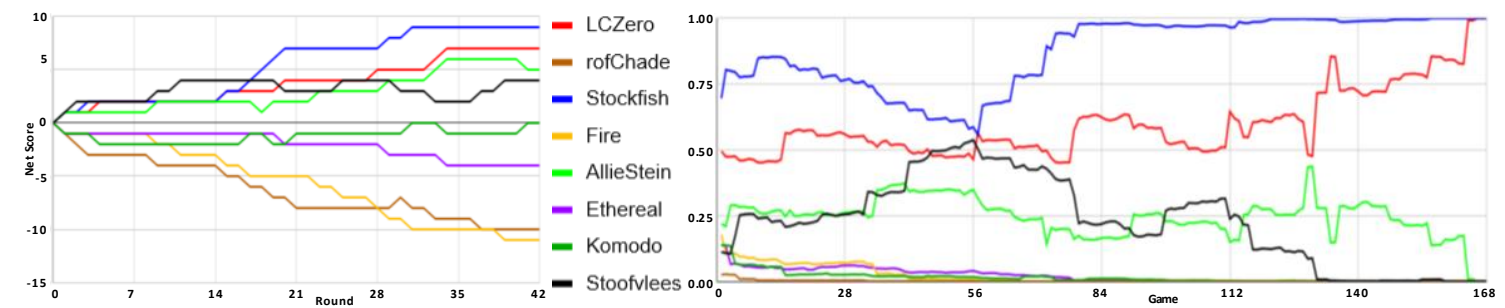

Fig. 7. Left: Premier engines' net wins, round by round. Right: engines' probability of promoting, game by game.

And so, the two Superfinalists were STOCKFISH - as had been a racing certainty after RR3 - and LEELA CHESS ZERO. Both were unbeaten but LEELA had not shown the cutting edge of TCEC17. Another close Superfinal was surely in prospect. Further, the runners-up seem to be getting closer and STOOFVLEES revealed its bold and sometimes capricious nature, resulting in many decisive games.

\section{THE SUPERFINAL}

Both contestants came to the stage in new versions. 'STOCKFISH 202006170741' precisely documents the time of its binding if not the time-zone. ${ }^{7}$ LCZERO had moved on from its Premier Division 'V0.25.1SV-T60-3010' version to 'V0.25.1-SVJIO-T60-3972-MLH', indicating not only that the neural net had evolved but also that the much heralded 'MLH' facility was now being deployed.

Some explanation of MLH is necessary. LEELA had grown another head, aka 'neural network' and its three heads now respectively covered 'search', 'evaluation' and 'moves left'. The aim of MLH was to make LEELA more decisive when closing out a win. While it had shown remarkably concerning and frustrating hesitancy in the past, a behaviour amiably described as spoofing, it had only fallen foul of Ruy Lopez' ancient, creaking 50-move-rule once in TCEC14 Sufi game 65. Two heads are said to be

${ }^{7}$ UTC is recommended as the Universal Time of Construction. 
better than one but whether three heads are better than two is debatable when they are not engaged in majority voting. As things transpired, it was debated at length in the TCEC chatroom.

Once again, your authors are happy - actually greatly relieved - that we can defer to the Superfinal commentators for their more informed chessic remarks (Chessdom, 2020; 'Gmthechesspuzzler', 2020; 'Kingscrusher', 2020; Sadler, 2020b; Sadler and Regan, 2020; Wool, 2020). ${ }^{8}$ Each bring their particular experience, insight and enjoyment of the game to their commentaries: we are greatly enlightened and delighted by them all. Long may they continue to reveal the patterns of play at the top level.

To bring some structure to the Superfinal, we discuss it in five phases of ten mini-matches each: Fig. 10 shows the trend of the event. All the evaluation graphs are available in supporting e-files (Haworth and Hernandez, 2020c): a few of these, and some highlighted positions and moves are given here in Figs. 8-9 as suggested moments and games to revisit. Noomen (2020 provided the set openings.

Phase 1: games 1-20, video commentaries for games 3, 4, 6, 8, 9, 13, 14, 17 and 18. Sadler (2020b) covers games 3-6, 8, 13-14, and 17-18 with particular plaudits for game 8 , a classic case of sacrificing for position. After two draws, both sides used an opening advantage of $\sim 0.8$ to bloody the other's escutcheon. LEELA's fortunes then flew South like a migrating Great Snipe with losses in games 6, 8 and 9, this last doing a rare opening favour for Black. Eyebrows were metaphorically and literally raised, even though five mini-matches qualify as a 'small sample' in the context of fifty. This would not be the first time that an incorrect parameter crept into the assembly room. LEELA then held the deficit to -3 , exchanging wins in mini-matches 7 and 9.
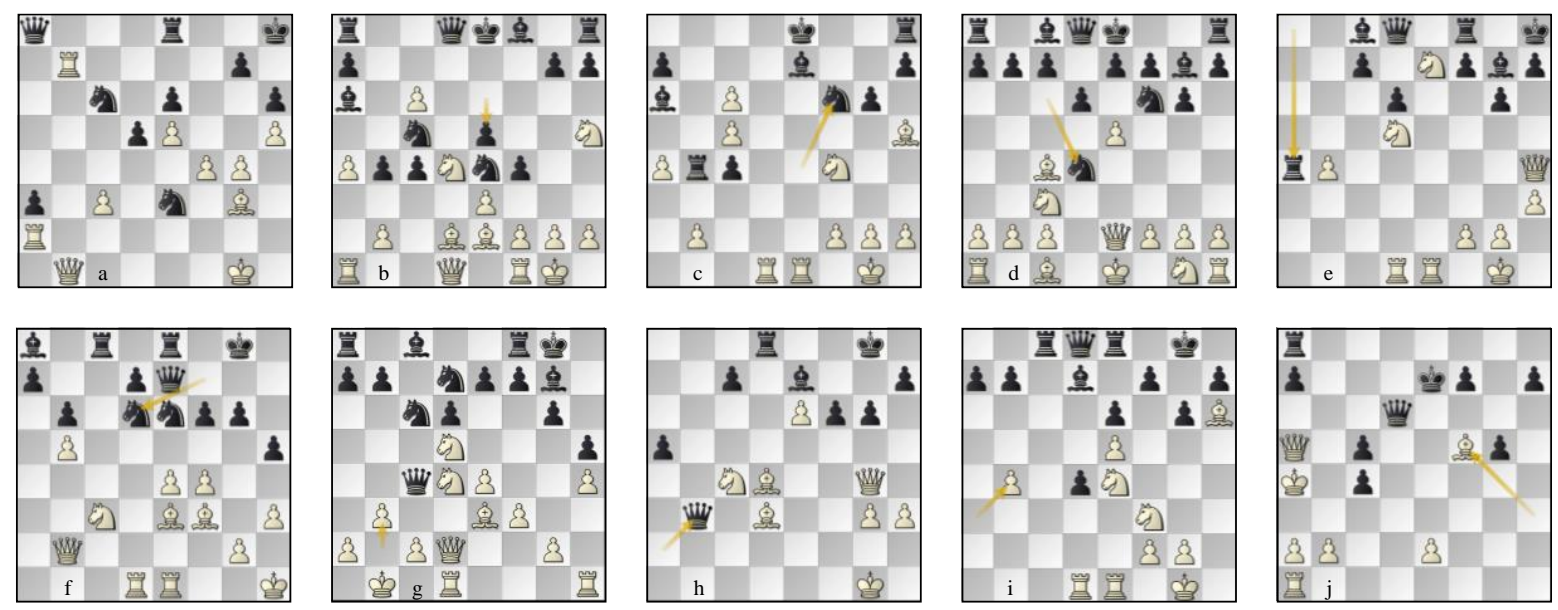

Fig. 8. Ten key moments: (a) game 06, 41.Rxg7; game 08 (b) 17.Bxb4 and (c) 24.Bxg6; (d) game 13, 7.exf6; (e) g14, 27.Rd3; (f) g24, 35.f5; (g) g34, 14...Qxd4; (h) g60, 33.Bxg6; (i) g65, 22..f5 and (j) g77, 31...Rb8.

The early games of Phase 2 edged STOCKFISH's net score to +4 . Videos cover games 22, 24, 34 and 40; Sadler (2020b) covers games 21-26, 29, 34 and 40. After game 26, Aloril did a precautionary reboot of the 'NN server' but the statistics did not reveal a significant change in performance. Thoughts then turned to the effect of LEELA's new MLH activity: the sense of the discussion was that MLH was overactive and consuming too much resource, especially given that LEELA was not exploiting the 32 threads

\footnotetext{
${ }^{8}$ At the time of writing, it is impossible to know all commentaries and we have probably not mentioned one or two commentators - so our apologies for omissions. Playlists and notifications are always useful.
} 
of its host CPU. Rather against expectations, LEELA then reduced its deficit to two with wins in game 29 and 33, curiously, neither covered yet in video commentaries.

Within phase 3, videos cover games 59 and 60. STOCKFISH moved away to clear favourite, taking its advantage out to +5 with unanswered wins in games 52, 56 and 58. LEELA continued to land blows in games 41, 45 and 59 - but not enough.
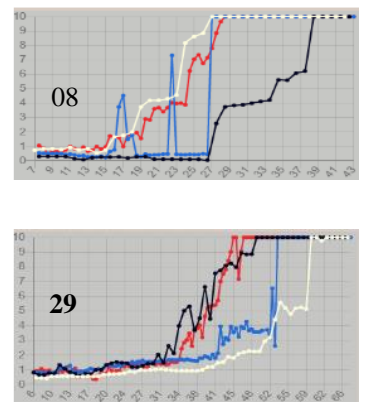
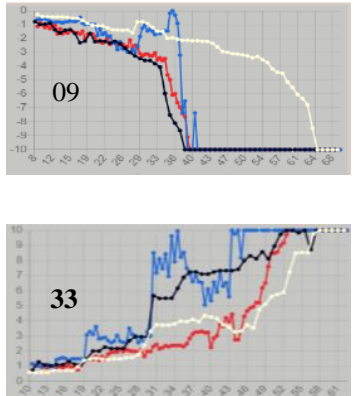
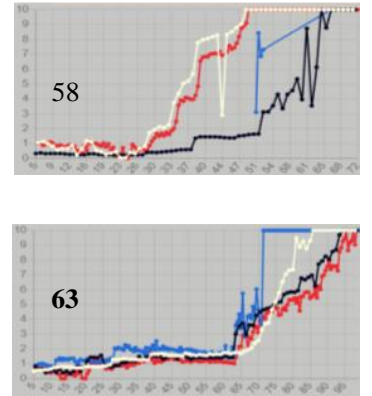
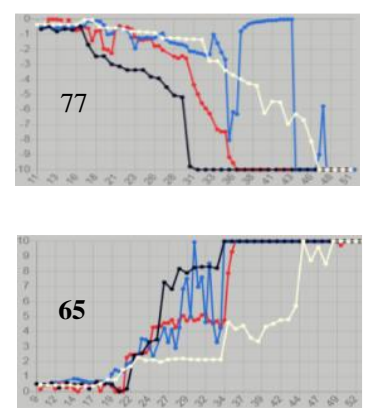

Fig. 9. Evaluation graphs for eight games that won 'same opening' mini-matches: STOCKFISH wins (first row), games 08, 09, 58 and 77; LEELA wins (second row), games 29, 33, 63 and 65.

In the front half of phase 4, LEELA kept supporters' hopes alive by cutting its deficit to three with unanswered wins in game 63 and the outstanding game 65 (Sadler, 2020b). However, STOCKFISH went back to +5 with wins in game 68 and, with Black, game 77 . Definitely too late to get reasonable odds on STOCKFISH. Two videos cover game 65.

In the final phase, STOCKFISH finished on +7 , notching a third win with Black in game 95 to formally determine the Superfinal result. LEELA made best use of the King's Indian opening in games 97-98 but by that time, STOCKFISH's supporters were again toasting their champion.

Table 7. The TCEC18 Superfinal result: the three 0-1 wins are underlined.

\begin{tabular}{|c|c|c|c|c|c|c|c|c|}
\hline Engines & Elo & Pts. & Elo \pm & \# wins & \multicolumn{2}{|c|}{ Wins in halved mini-matches } & \multicolumn{2}{|c|}{ Wins in won mini-matches } \\
\hline $\begin{array}{l}\text { LCZero v0.25.1- } \\
\text { svjio-t60-3972- }\end{array}$ & 3813 & $461 / 2$ & -18 & $11+5$ & $\begin{array}{c}03,13,17,25,41,45 \\
59,61,71,75,93\end{array}$ & $\begin{array}{l}\text { E92, B06, B99, } \\
\text { B10, C45, B06, }\end{array}$ & $29,33,63,65,97$ & B07, B77, C10, E11, E97 \\
\hline $\begin{array}{c}\text { Stockfish } \\
202006170741\end{array}$ & 3801 & $53 \frac{1}{2}$ & +18 & $11+12$ & $\begin{array}{c}04,14,18,26,42,46 \\
60,62,72,76,94\end{array}$ & $\begin{array}{c}\text { B00, A56, C40/1, } \\
\text { B01, A97 }\end{array}$ & $\begin{array}{r}06,08, \underline{09}, 24,52,56, \\
58,68,77,88,92,95\end{array}$ & $\begin{array}{l}\mathrm{C} 18, \mathrm{D} 31, \mathrm{C} 34, \mathrm{E} 12, \mathrm{~B} 40, \mathrm{C} 41, \\
\mathrm{~A} 80, \mathrm{~B} 29, \mathrm{~A} 33, \mathrm{C} 37, \mathrm{C} 16, \mathrm{C} 42\end{array}$ \\
\hline
\end{tabular}

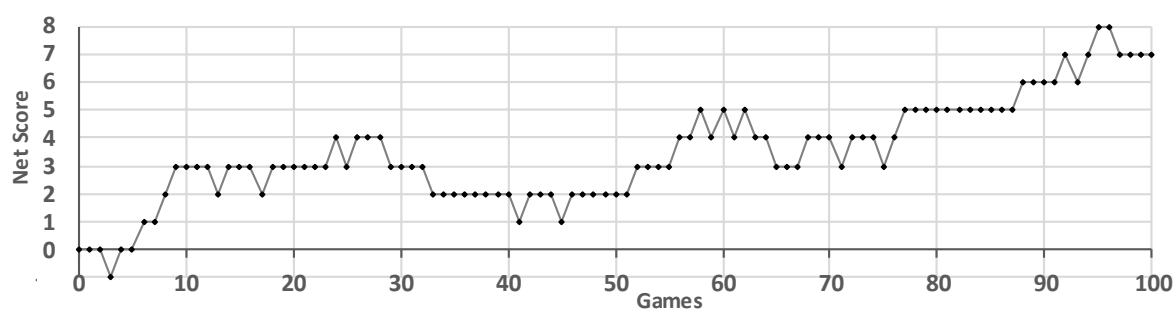

Fig. 10. The TCEC18 Grand Champion STOCKFISH's net score as the Superfinal progressed.

Overall, STOCKFISH won 12 game-pairs to LEELA's five and thereby regained the title of TCEC Super Champion, 531/2-461/2. Even so, this suggests an Elo difference of only $24-25$ between the engines and we should not forget that LEELA did beat STOCKFISH in 16 games. There is little doubt that STOCKFISH has moved on in terms of its tactical vision but maybe LEELA also stepped back a bit. Figure 9 shows 
that the engines' views of the positions sometimes differed radically, even if LEELA's probabilities have not been precisely converted to centipawns. Nelson here sees that STOCKFISH is not afraid to diverge from established theory and is consistently improving his openings database. We are privileged to have Matthew Sadler's (2020b) GM-level commentary which gives plenty of illumination and reasons to revisit these games, see also Figures 8-9 here.

\section{SUMMARY}

Once again, STOCKFISH has triumphed in TCEC, topping the league for the $8^{\text {th }}$ time. Its trophy cabinet now records its Super Champion titles for TCEC seasons 6, 9,11-14, 16 \& 18. This is a great tribute to STOCKFISH's core development team and to all those involved in the crowd-sourced testing, a process which has proved itself robust and healthy over a long period now.

Table 8. Generic statistics for each phase of TCEC18: results, terminations and average game-length.

\begin{tabular}{|c|c|c|c|c|c|c|c|c|c|c|c|c|c|c|c|}
\hline & \multirow{2}{*}{ TCEC 18} & \multicolumn{2}{|c|}{ Qualification } & \multicolumn{2}{|c|}{ League 3} & \multicolumn{2}{|c|}{ League 2} & \multicolumn{2}{|c|}{ League 1} & \multicolumn{2}{|c|}{ Division $\mathbf{P}$} & \multicolumn{2}{|c|}{ Superfinal } & \multicolumn{2}{|c|}{ Overall } \\
\hline & & \# & $\%$ & $\#$ & $\%$ & $\#$ & $\%$ & $\#$ & $\%$ & \# & $\%$ & $\#$ & $\%$ & $\#$ & $\%$ \\
\hline \multirow{10}{*}{$\begin{array}{l}\stackrel{\mathscr{a}}{\vec{z}} \\
\cong \\
\cong\end{array}$} & \# games & 90 & & 90 & & 90 & & 90 & & 168 & & 100 & & 628 & \\
\hline & Draws & 37 & 41.1 & 59 & 65.6 & 54 & 60.0 & 70 & 77.8 & 133 & 79.2 & 61 & 61.0 & 414 & 65.9 \\
\hline & Wins & 53 & 58.9 & 31 & 34.4 & 36 & 40.0 & 20 & 22.2 & 35 & 20.8 & 39 & 39.0 & 214 & 34.1 \\
\hline & $1-0$ & 34 & 37.8 & 22 & 24.4 & 20 & 22.2 & 13 & 14.4 & 31 & 18.5 & 36 & 36.0 & 156 & 24.8 \\
\hline & $0-1$ & 19 & 21.1 & 9 & 10.0 & 16 & 17.8 & 7 & 7.8 & 4 & 2.4 & 3 & 3.0 & 58 & 9.2 \\
\hline & White performance & 52.5 & 58.3 & 51.5 & 57.2 & 47.0 & 52.2 & 48.0 & 53.3 & 97.5 & 58.0 & 66.5 & 66.5 & 363 & 57.8 \\
\hline & Black performance & 37.5 & 41.7 & 38.5 & 42.8 & 43.0 & 47.8 & 42.0 & 46.7 & 70.5 & 42.0 & 33.5 & 33.5 & 265 & 42.2 \\
\hline & TCEC draw & 16 & 17.8 & 33 & 36.7 & 25 & 27.8 & 45 & 50.0 & 87 & 51.8 & 51 & 51.0 & 257 & 40.9 \\
\hline & $3 \mathrm{x}$ repetition & 11 & 12.2 & 14 & 15.6 & 9 & 10.0 & 14 & 15.6 & 16 & 9.5 & 5 & 5.0 & 69 & 11.0 \\
\hline & 50-move rule & 2 & 2.2 & 0 & 0.0 & 0 & 0.0 & 0 & 0.0 & 2 & 1.2 & 2 & 2.0 & 6 & 1.0 \\
\hline & Stalemate & 0 & 0.0 & 0 & 0.0 & 0 & 0.0 & 0 & 0.0 & 0 & 0.0 & 0 & 0.0 & 0 & 0.0 \\
\hline \multirow{9}{*}{ 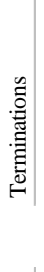 } & EGT adj., 'draw' & 8 & 8.9 & 12 & 13.3 & 20 & 22.2 & 11 & 12.2 & 28 & 16.7 & 3 & 3.0 & 82 & 13.1 \\
\hline & EGT adjudication & 19 & 21.1 & 17 & 18.9 & 27 & 30.0 & 11 & 12.2 & 29 & 17.3 & 5 & 5.0 & 108 & 17.2 \\
\hline & TCEC win & 41 & 45.6 & 26 & 28.9 & 28 & 31.1 & 20 & 22.2 & 33 & 19.6 & 37 & 37.0 & 185 & 29.5 \\
\hline & EGT adj., 'win' & 11 & 12.2 & 5 & 5.6 & 7 & 7.8 & 0 & 0.0 & 1 & 0.6 & 2 & 2.0 & 26 & 4.1 \\
\hline & Tech. default & 0 & 0.0 & 0 & 0.0 & 1 & 1.1 & 0 & 0.0 & 0 & 0.0 & 0 & 0.0 & 1 & 0.2 \\
\hline & Manual adj. & 0 & 0.0 & 0 & 0.0 & 0 & 0.0 & 0 & 0.0 & 0 & 0.0 & 0 & 0.0 & 0 & 0.0 \\
\hline & Mate & 1 & 1.1 & 0 & 0.0 & 0 & 0.0 & 0 & 0.0 & 1 & 0.6 & 0 & 0.0 & 2 & 0.3 \\
\hline & Loss on time & 0 & 0.0 & 0 & 0.0 & 0 & 0.0 & 0 & 0.0 & 0 & 0.0 & 0 & 0.0 & 0 & 0.0 \\
\hline & Resignation & 0 & 0.0 & 0 & 0.0 & 0 & 0.0 & 0 & 0.0 & 0 & 0.0 & 0 & 0.0 & 0 & 0.0 \\
\hline \multirow{4}{*}{$\begin{array}{l}\overrightarrow{5} \\
\overline{00} \\
\bar{\Xi}\end{array}$} & Moves & 69.3 & & 60.9 & & 62.6 & & 57.2 & & 68.7 & & 75.6 & & 66.2 & \\
\hline & Time-budget (h) & 1.19 & & 1.17 & & 1.17 & & 1.66 & & 3.38 & & 3.25 & & 2.17 & \\
\hline & Clock-time used (h) & 1.09 & 91.1 & 1.00 & 85.8 & 1.00 & 85.4 & 1.38 & 83.1 & 2.89 & 85.6 & 3.13 & 96.3 & 1.91 & 88.3 \\
\hline & C-time not used (h) & 0.11 & 8.9 & 0.17 & 14.2 & 0.17 & 14.6 & 0.28 & 16.9 & 0.49 & 14.4 & 0.12 & 3.7 & 0.25 & 11.7 \\
\hline
\end{tabular}

Table 9. The shortest and longest 1-0, drawn and 0-1 games in each phase of TCEC18.

\begin{tabular}{|c|c|c|c|c|c|c|c|c|c|c|c|c|c|c|c|c|c|c|}
\hline \multirow{2}{*}{ Div. } & \multicolumn{6}{|c|}{ 1-0 } & \multicolumn{6}{|c|}{$1 / 2-1 / 2$} & \multicolumn{6}{|c|}{$0-1$} \\
\hline & \multicolumn{3}{|c|}{ Shortest } & \multicolumn{3}{|c|}{ Longest } & \multicolumn{3}{|c|}{ Shortest } & \multicolumn{3}{|c|}{ Longest } & \multicolumn{3}{|c|}{ Shortest } & \multicolumn{3}{|c|}{ Longest } \\
\hline Q & $21 / 5.1$ & Tu-We & 33 & $51 / 11.1$ & CF-We & 116 & $75 / 15.5$ & As-Tu & 17 & $57 / 12.2$ & $\mathrm{Co}-\mathrm{Tu}$ & 196 & $56 / 12.1$ & We-Fa & 41 & $30 / 6.5$ & Tu-As & 108 \\
\hline 2 & $41 / 9.1$ & Wa-Go & 41 & $59 / 12.4$ & Ch-Wa & 132 & $16 / 4.1$ & Go-Ch & 20 & $31 / 7.1$ & Wi-Go & 167 & $37 / 8.2$ & Va-Ch & 46 & $06 / 2.1$ & Go-Bo & 80 \\
\hline 1 & $27 / 6.2$ & $\mathrm{Bo}-\mathrm{Fr}$ & 47 & $40 / 8.5$ & De-Ru & 94 & $28 / 6.3$ & $\mathrm{Sc}-\mathrm{Fi}$ & 17 & $85 / 17.5$ & $\mathrm{Ru}-\mathrm{De}$ & 197 & $76 / 16.1$ & Pe-De & 45 & $83 / 17.3$ & Fr-rf & 71 \\
\hline $\mathbf{P}$ & $164 / 41.4$ & Ko-AS & 36 & $42 / 11.2$ & $\mathrm{~Sv}-\mathrm{Fi}$ & 104 & $146 / 37.2$ & Ko-Et & 29 & $141 / 36.1$ & ro-Lc & 304 & $04 / 1.4$ & $\mathrm{Ko}-\mathrm{Sv}$ & 63 & $05 / 2.1$ & ro-Sv & 93 \\
\hline O'all & $\mathrm{Q}, 21$ & Tu-We & 33 & 2,59 & Ch-Wa & 132 & $\mathrm{Q}, 75$ & As-Tu & 17 & SF, 73 & Lc-St & 357 & $\mathrm{Q}, 56$ & We-Fa & 41 & $\mathrm{Q}, 30$ & Tu-As & 108 \\
\hline
\end{tabular}

Tables 8 and 9 provide the standard statistics on the TCEC18 Championship as a whole. All the decisive TCEC games have been played out using FRITZ17 at a search-depth of 24 ply (Haworth and Hernandez, 2020c) and all their entries to 7-man chess have been given 'DTM' Depth to Mate (Lomonosov, 2012) and 'DTZ' Depth to Zeroing of the ply count (de Man et al, 2018) depths. 
In the first bonus postscript event, albeit at the super-Rapid tempo of $12^{\prime}+3^{\prime \prime} / \mathrm{m}$, STOCKFISH 20200701 beat KOMODO 2566.00 71-29. Note that STOCKFISH had already moved on from its Superfinal version. KOMODO had also evolved from its Premier Division 2551.00 version but was 'only' running on 88 threads this time, a disadvantage of maybe 50 Elo to add to its nominal deficit of 48 Elo. These Elo estimates would suggest a score of 63-37 but we believe that the faster tempo may also have favoured the stronger engine. Discuss!

In the second bonus event, by popular request the TCEC18 'top 4' contested at $60^{\prime}+5^{\prime \prime} / \mathrm{m}$. It was expected to be close and lots of time was generously allocated for this. Indeed, it was close: LEELA CHESS ZERO V0.26.0-SV-T60-4229-MLH and ALLIESTEIN on +3 beat STOCKFISH and STOOFVLEES on -3 after seven double round-robins, 84 games with only six wins. This result looked like improvements for all except STOCKFISH.

TCEC continues to be the major force for change in the computer chess world. The stronger platforms continue to challenge engine authors to take advantage of the multi-thread parallelism available to them. Those wishing to study neural nets more closely could well start with the 3Blue1Brown (2020) videos or CPW (2020b). Off-stage, there are experiments with even bigger platforms than TCEC's including noob's 384-thread machine and a 4,096-thread NUMA supercomputer. LEELA is not taking advantage of the 32 threads available in the CPU serving the GPUs in the platform available to the neural-network engines so there is clear room for improvement in this area.

In a third bonus event, TCEC featured an experimental STOCKFISHNNUE, a fusion of the STOCKFISH engine and an 'easily updated', CPU-based NNUE neural network as evaluating agent. In 56 games against no less than the top four, STOCKFISHNNUE won three games against STOOFVLEES and lost only one to ALLIESTEIN, a remarkable debut for a new concept. ${ }^{9}$ NNs running on CPUs rather than GPUs are very welcome as they will make NN-engines more usable for many of us: LCZEROCPU is another such engine. The ex-Shogi/Y ANEURAOU NNUE (Cong, 2020) will surely appear elsewhere.

It is our pleasure to thank all those who made this TCEC season (Wikipedia, 2020) so memorable:

- principal sponsor 'noobpwnftw' and all those contributing to the crowd funding,

- the authors, trainers and cloud resources behind the forty participating engines,

- the operations team who ran the actual events increasingly smoothly,

- the commentators whose observations clarify so much, and

- the increasing number of fans who contribute to the wisdom and humour of the chat room.

The fun TCEC Cup 6 knockout event follows (Haworth and Hernandez, 2020d) and we will meet again in TCEC19 which will bring its own set of exciting formats, innovations and surprises.

\section{REFERENCES}

3Blue1Brown (2017). https://www.youtube.com/watch? $v=a i r c A r u v n K k \& t=991 s$. The first of four videos on neural networks.

'Aloril' (2020). https://tcecbayeselo.chessdom.org/. Bayeselo simulation forecasts.

Chessdom (2020). https://wiki.chessdom.org/TCEC_Season_18_Game_coverage.

\footnotetext{
${ }^{9}$ However, the indications are that STOCKFISHNNUE cannot take part in the TCEC Championship while Grand Champion STOCKFISH is on the stage - as they share a common engine.
} 
Cong, V. C. (2020). https://github.com/ynasu87/nnue. NNUE Github site.

CPW (2020a). https://tinyurl.com/icga046. Biographies of chess engines, authors and developers. CPW (2020b). https://www.chessprogramming.org/Neural_Networks. Tutorial on neural networks.

de Man, R., Fiekas, N. and Guo, B. (2018). https://tinyurl.com/icga007. Fiekas' interface to 'Syzygy formatted' de Man sub-7-man and Guo 7-man DTZ 50 " EGTs.

'Gmthechesspuzzler' (2020). https://tinyurl.com/icga068. TCEC18 video-commentary playlist.

Haworth, G. $M^{\mathrm{c} C}$ and Hernandez, N. (2020a). The 17 $7^{\text {th }}$ TCEC event: TCEC17. ICGA Journal, 42(2-3), 181-191. http://centaur.reading.ac.uk/89999/ adds pgn files, further data and statistics.

Haworth, G. $\mathrm{M}^{\mathrm{c}} \mathrm{C}$ and Hernandez, N. (2020b). TCEC Cup 5. ICGA Journal, 42(2-3), 207-210. http://centaur.reading.ac.uk/90606/ adds pgn files, further data and statistics.

Haworth, G. $\mathrm{M}^{\mathrm{c}} \mathrm{C}$ and Hernandez, N. (2020c). The $18^{\text {th }}$ TCEC event: TCEC 18. ICGA Journal, 42(2-3), 211-222. http://centaur.reading.ac.uk/91839/adds pgn files, further data and statistics.

Haworth, G. $\mathrm{M}^{\mathrm{c}} \mathrm{C}$ and Hernandez, N. (2020d). TCEC Cup 6. ICGA Journal, 42(2-3), 237-241. http://centaur.reading.ac.uk/91840/ adds pgn files, further data and statistics.

Intel (2016). https://tinyurl.com/icga059. Intel's specification of the XEON® E5-4669v4 processor.

'Kingscrusher' (2020). https://tinyaurl.com/icga073. TCEC18 video-commentary playlist.

'Imabacus' (2020). https://tinyurl.com/icga064. Spreadsheets and graphics of TCEC18 progress and promotion prospects.

Lomonosov (2012). http://tb7.chessok.com/. Facility for querying sub-8-man DTM EGTs.

Müller, K. and Konoval, Y. (2019). Understanding Rook vs Minor Piece Endgames. Russell Enterprises. See also http://centaur.reading.ac.uk/82423/.

Noomen, J. (2020). https://tinyurl.com/icga065. Jeroen Noomen on his choice of openings.

Nvidia (2019). https://www.nvidia.com/en-us/data-center/v100/. Nvidia's V100 specification.

Sadler, M. (2020a). The TCEC17 Computer Chess Superfinal: a Perspective. ICGA Journal, v42(\$\$) $\$ \$-\$$.

Sadler, M. (2020b). The TCEC18 Computer Chess Superfinal: a Perspective. Submitted to the ICGA Journal.

Sadler, M. and Regan, N. (2016). Chess for Life. Gambit.

Sadler, M. and Regan, N. (2019). Game Changer: AlphaZero's Groundbreaking Chess Strategies and the Promise of AI. New in Chess. ECF 2019 Book of the Year; winner of FIDE's 2019 AverbakhBoleslavsky Award. See also https://www.youtube.com/watch?v=FW-hDMbZHAY.

Sadler, GM M. and Regan, WIM N. (2020). https://tinyurl.com/icga060. 'Chess Giant' videocommentaries on TCEC Premier League and Superfinal games, especially CG\#21-36.

Wikipedia (2020). https://en.wikipedia.org/wiki/TCEC_Season_18. TCEC Season 18 report.

'Wool, A.' (2020) http://mytcecexperience.blogspot.co.uk/. AW's ‘TCEC Experience' blog. 